\title{
Theoretical and Experimental Study of Explosion Limits and the Inhibition of Flammable Refrigerants
}

\author{
Guansan Tian1,2,3, Xingquan Li1,2, Yunfeng Gao1, Fengxia Zhang1 \\ ${ }^{1}$ School of Thermal Energy Engineering, Shandong Jianzhu University, Jinan, China \\ ${ }^{2}$ Key Laboratory of Renewable Energy Utilization Technology in Building of National Education Ministry, \\ Shandong Jianzhu University, Jinan, China \\ ${ }^{3}$ Shandong Provincial Key Laboratory of Building Energy-Saving Technology, Shandong Jianzhu University, Jinan, China \\ Email: gyf0627@139.com
}

How to cite this paper: Tian, G.S., Li, X.Q., Gao, Y.F. and Zhang, F.X. (2016) Theoretical and Experimental Study of Explosion Limits and the Inhibition of Flammable Refrigerants. Journal of Software Engineering and Applications, 9, 501-515.

http://dx.doi.org/10.4236/jsea.2016.910033

Received: August 25, 2016

Accepted: October 22, 2016

Published: October 25, 2016

Copyright $\odot 2016$ by authors and Scientific Research Publishing Inc. This work is licensed under the Creative Commons Attribution International License (CC BY 4.0).

http://creativecommons.org/licenses/by/4.0/

\begin{abstract}
In this study, we analyze factors affecting the explosion limits of flammable refrigerants. We conclude that any method used for measuring flammable refrigerant explosion limits has its conditional restrictions. Flammable refrigerants in the atmosphere can also explode under certain conditions, when the concentration is approaching the explosion limits. An experimental study on the explosion limits of six kinds of flammable refrigerants is carried out with a mixture of refrigerant and combustible refrigerant, which has a similar effect to a flame retardant. An experimental apparatus was designed to test the explosion limits of mixtures made from three different nonflammable refrigerants and six different flammable refrigerants. Two practical models were developed to estimate the critical concentration for inhibiting explosion of refrigerant mixtures: one was made up of two flammable components with one nonflammable component, and the second was made up of one flammable component with two nonflammable components.
\end{abstract}

\section{Keywords}

Flammable Refrigerants, Explosion Limits, Impact Factors, Inhibition

\section{Introduction}

Some refrigerants that are currently used as substitutes for CFCs and HCFCs are flammable. If these flammable refrigerants leak into the environment and the resulting air to refrigerant ratio is within a certain limiting range, flames are able to propagate [1]. If however, the mixing ratio falls outside the limiting range, with the concentration of 
flammable gases in the mixture being too high or too low, the flame will lose its ability to propagate and will stop burning. The reason for this is that the calorific capacity of the mixture is too low, and the heat from the oxidation reaction is not sufficient to raise the unburned mixture to ignition temperature.

The lowest concentration of flammable gas in the air at which flames can propagate, is called the Minimum Concentration of Flame Propagation. Correspondingly, the highest concentration is called the Maximum Concentration of Flame Propagation. These limiting concentrations for flame propagation are also referred to as the Flammability Concentration Limit. A mixture of flammable gases with air, which is within the Flammability Concentration Limit, could ignite instantaneously and cause an explosion under certain circumstances (for example, in a sealed vessel). Therefore, at atmospheric pressure, the Flammability Concentration Limit can be called the explosion limit. It is important to determine and control the explosion limits of flammable refrigerants so that they can be safely used.

\section{Factors Influencing the Explosion Limits of Flammable Refrigerants}

The explosion limits of flammable refrigerant gases are related to the following factors.

\subsection{Categories and Chemical Properties of Flammable Refrigerants}

The molecular structure and reactivity of flammable gases are closely related to their explosion limits. As shown experimentally, hydrocarbons with a C-C single bond are very stable because the carbon bond is stable with low reactivity. Since these molecules are hard to destruct, they have a relatively narrow range between upper and lower explosion limits when compared to other hydrocarbons. In contrast, hydrocarbons with $\mathrm{C} \equiv \mathrm{C}$ triple bonds have a relatively large range, as their carbon bonds are fragile, and their molecules are easy to break, having strong chemical reactivity [2]. Finally, the range for hydrocarbons with $\mathrm{C}=\mathrm{C}$ double bonds is somewhere between that of the single bond and triple bond hydrocarbons. For the same hydrocarbons, an increase in the number of carbon atoms reduces the explosion limit. In addition, explosion limits are also related to thermal conductivity $\lambda$ (or thermal diffusivity a), if $\lambda$ increases, the range will be wider [3].

\subsection{Purity of Flammable Gases}

The purity of flammable gases could affect their explosion limits, because the presence of inert gases in unpurified flammable gases will decrease the range of explosion limits. Inert gases like nitrogen, carbon dioxide and water vapor influence the explosion limits by diluting the flammable gases, isolating oxygen, and cooling the gases. When there are alkyl halides in the flammable gases, these alkyl halides can not only dilute, isolate and cool, but more importantly, they can also chemically inhibit combustion and explosion reactions. Furthermore, alkyl halides also have the ability to increase the minimum explosion limits and ignition energies of flammable refrigerants, which will sig- 
nificantly reduce the explosion limit range. For these reasons, most of the gas-extinguishing systems comprise alkyl halides.

\subsection{Uniformity of Flammable Refrigerant Vapor Mixed with Air}

If flammable refrigerant vapors are mixed homogeneously with air and the concentration of flammable mixtures at some point reaches the explosion limits, the concentration of flammable mixtures in the whole mixing space will reach explosion limits. In this case, combustion and explosion reactions will occur in this gas mixture space at the same time and will continue without interruption, which leads to an increase in the explosion limit range. However, if they are mixed heterogeneously, the concentration of flammable mixtures in that mixture will reach or exceed the explosion limits, and the concentration of other flammable gases will not reach explosion limits. Consequently, the reactions will be interrupted, which means the mixtures will have narrower ranges of explosion limits.

\subsection{Form, Energy and Position of Ignition Source}

Ignition sources that can cause flammable refrigerant vapors to combust and explode are mainly open fires, lighted cigarettes, lighted matches and burning candles. Electronic sparks made by electrical switches, electrical wire shorts and static electricity, and sparks generated by mechanical impacts and friction can also cause fire. Different ignition sources have different ignition temperatures or energies [4], for example, the temperature of an open fire is about $1000^{\circ} \mathrm{C}$, a lighted cigarette is $200^{\circ} \mathrm{C}-600^{\circ} \mathrm{C}$, a lighted match or a burning candle is $600^{\circ} \mathrm{C}-800^{\circ} \mathrm{C}$, and an electronic spark or a mechanical spark is $1000^{\circ} \mathrm{C}-1200^{\circ} \mathrm{C}$. Once the temperature of an ignition source reaches the ignition temperature of flammable gases, the higher the energy of the ignition sources, the easier it will be to ignite the flammable gases. For example, since the energy of an open fire is higher than that of a normal spark, the range of explosion limits is greater. Moreover, although the temperature of an electric spark is high, it will have low energy and a small range of explosion limits when the spark is not constant.

\subsection{Geometries and Sizes of Explosion Vessels}

Explosion limits of flammable gases are measured in closed vessels. The geometry, size and thermal conductivity of a vessel's wall material influence the heat dissipation capacity of a flammable mixture. If the surface area of a vessel is large, and the wall material's thermal conductivity $\lambda$ is high, more heat dissipation will result, and more energy will be needed to maintain the combustion or explosion reactions. As a result, the range of explosion limits will be small. On the other hand, if the surface area is smaller, and the thermal conductivity is low, the range of explosion limits will be greater.

\subsection{Temperature, Pressure and Humidity of the Flammable Gases Mixture}

Raising the temperature of the flammable mixture can increase the rate of combustion 
or explosion and increase the temperature of the reaction, which results in expanding the range of explosion limits. With increasing pressure of a flammable mixture [5], the intermolecular distance will be reduced and the reaction speed will increase. Thus, both of the upper and lower explosion limits will be raised. However, the upper explosion limit changes more significantly than the lower limit, which results in an increase in the range of explosion limits. When the humidity increases, the range of the explosion limit will be narrower because water vapor can dilute the flammable mixture and isolate the oxygen.

Currently, most of the published data on explosion limits of flammable refrigerants is measured using small ignition sources (most of initiation energy is under $100 \mathrm{~J}$ ), in small explosion vessels $\left(0.001-0.005 \mathrm{~m}^{3}\right)$, at normal temperatures. According to relevant research results, the data is close to real life situations when the initiation energy is $10,000 \mathrm{~J}$ using a vessel of $1 \mathrm{~m}^{3}$. Therefore, when choosing the parameters of a flammable refrigerant's explosion limits, it is essential to determine the test conditions and consider safety factors. Based on national fire defense regulations, it is necessary to consider the mixing properties of leaked flammable gases with air, and the difference between the experimental value for the explosion limits and the actual value. Taking this into consideration, the controlling range is between 0.5 times the lower explosion limit to 1.5 times the upper explosion limit.

\section{Experimental Research on Refrigerant Combustion Inhibition}

A variety of Halon substitutes are currently used as fire-extinguishing agents. Examples include R134a in FE-24, R125 in FE-25, R227 in MT200 and $\mathrm{CF}_{3} \mathrm{I}$ [6]. Halon has both a physical and chemical role in inhibiting combustion and in the extinguishing mechanism: the physical role is the same as for an inert gas; the chemical role takes the form of a chemical reaction at high flame temperature, decomposing and activating free radicals such as $\mathrm{Br}^{\circ}, \mathrm{Cl}^{\circ}, \mathrm{I}^{\circ}$ and other matter in the combustion process, and eliminating free radicals such as $\mathrm{H}^{\circ}$ and $\mathrm{OH}^{\circ}$. Both of these roles can result in chemical chain interruption and fire extinguishing. This experiment uses the haloalkane $\mathrm{CF}_{3} \mathrm{I}$ to illustrate the inhibitory effect on combustible hydrocarbon gases. When flammable hydrocarbon gas in the air is burning and exploding, it will initially produce active center free radicals:

$$
\mathrm{HR}+\mathrm{O}_{2} \rightarrow \mathrm{H}^{\circ}+2 \mathrm{O}^{\circ 0}+\mathrm{R}^{\circ}
$$

This is the initiation process of a chain reaction, and further reaction results in the formation of free radicals:

$$
\begin{array}{r}
\mathrm{H}^{\mathrm{o}}+\mathrm{O}^{\mathrm{oo}} \rightarrow \mathrm{OH}^{\mathrm{o}} \\
2 \mathrm{OH}^{\mathrm{o}} \rightarrow \mathrm{H}_{2} \mathrm{O}+\mathrm{O}^{\mathrm{oo}}
\end{array}
$$

The last step of this reaction can release a huge amount of heat and regenerate $\mathrm{O}^{\circ 0}$ free radicals. If there are no inhibitors or buffering agents, the chain reaction will continue automatically, with the flammable gas combusting or exploding. If the combustible gas contains inhibitors, these inhibitors will be decomposed by heat. The inhibition 
of the chemical reaction is as follows:

$$
\mathrm{CF}_{3} \mathrm{I} \rightarrow \mathrm{CF}_{3}{ }^{0}+\mathrm{I}^{\mathrm{o}}
$$

The $\mathrm{I}^{\circ}$ free radical then reacts with the combustible gas to produce $\mathrm{HI}$ :

$$
\mathrm{RH}+\mathrm{I}^{\mathrm{o}} \rightarrow \mathrm{HI}+\mathrm{R}^{0}
$$

$\mathrm{HI}$ reacts with $\mathrm{OH}^{\circ}$ from Formula (2), removing $\mathrm{OH}^{\circ}$ and regenerating $\mathrm{I}^{\mathrm{o}}$. The reaction is:

$$
\mathrm{OH}^{\mathrm{o}}+\mathrm{HI} \rightarrow \mathrm{H}_{2} \mathrm{O}+\mathrm{I}^{\mathrm{o}}
$$

$\mathrm{I}^{\circ}$ from this regeneration and $\mathrm{I}^{\circ}$ from decomposition of $\mathrm{CF}_{3} \mathrm{I}$, will take part in a chain reaction, which according to Formulas (5) and (6) result in the constant elimination of active free radicals, such as $\mathrm{OH}^{\circ}, \mathrm{H}^{\circ}, \mathrm{O}^{\circ}$. The chain reaction responsible for the suppression of fire is the opposite of the chain reaction which forms part of the process of combustion and explosion. Previous inhibition of "chain" interrupted latter a "burning chain", to control the combustion and fire. The chemical inhibitory effect of $\mathrm{CF}_{3} \mathrm{I}$ on the flammability of hydrocarbons is also known as a negative catalytic effect.

To quantitatively analyze fire-suppressant mixtures that affect the explosion limit of flammable refrigerants, this experiment will determine the explosion limit of flammable gases by the national standard GB/T12447-90. Six flammable refrigerants, R290, R600, R600a, R32, R143a and R152a, are used in this experiment. Using R134a, R125 and R227ea to influence the explosion limits of the six flammable refrigerants, we obtained the following results.

\subsection{Inhibitory Effect of R134a on Six Flammable Refrigerants' Explosion Limits}

The inhibitory effect of R134a on the six flammable refrigerants' explosion limit is shown in Figure 1 and Figure 2.

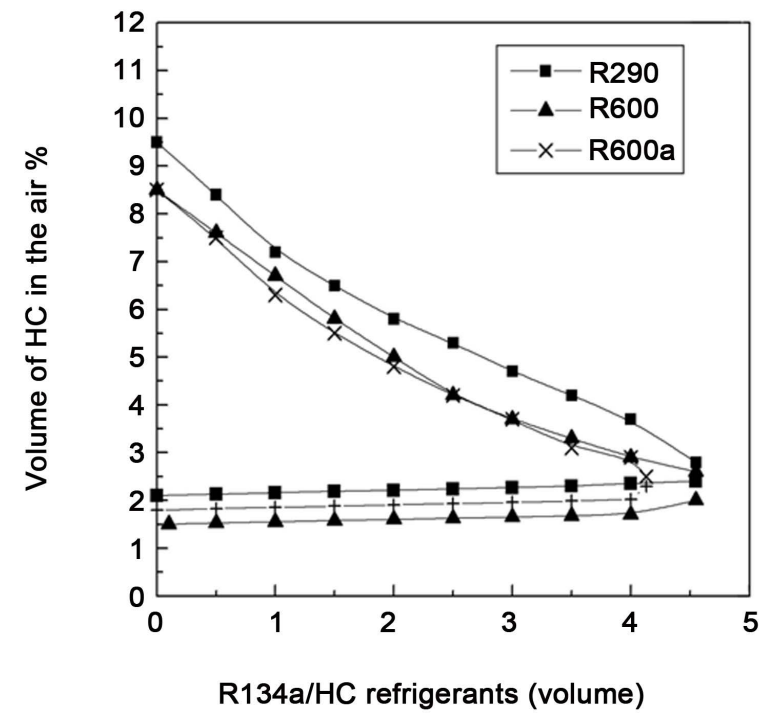

Figure 1. Effect of R134a on HC explosion limit. 


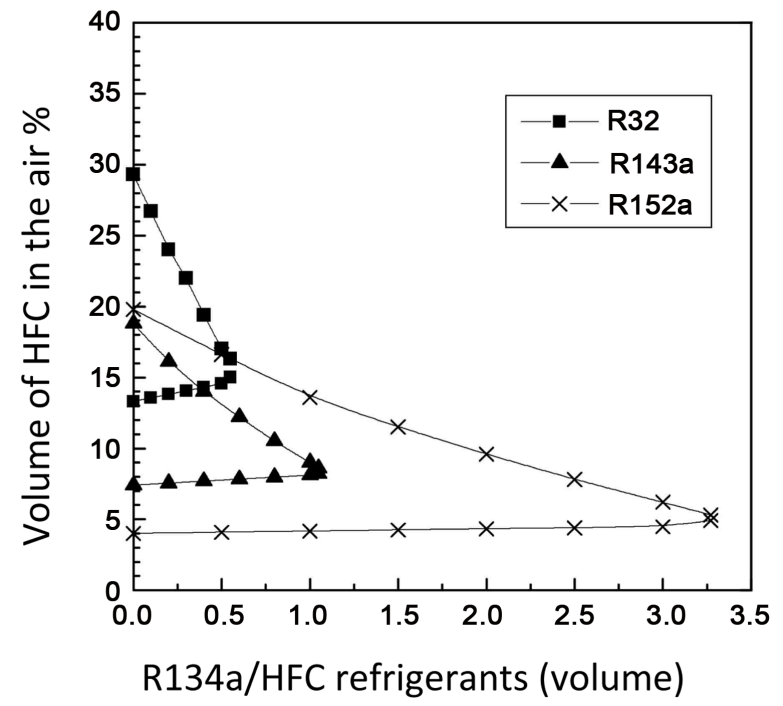

Figure 2. Effect of R134a on HFC explosion limit.

\subsection{Inhibitory Effect of R125 on Six Flammable Refrigerants' Explosion Limits}

The inhibitory effect of R125 on the six flammable refrigerants' explosion limit can be seen in Figure 3 and Figure 4.

\subsection{Inhibitory Effect of R227ea on Six Flammable Refrigerants' Explosion Limits}

The inhibitory effect of R227ea on the six flammable refrigerants' explosion limits is shown in Figure 5 and Figure 6.

\subsection{Analysis of the Experimental Results}

Figures 1-6 show the experimental curves for the impact of three nonflammable refrigerants on the explosion limits of six flammable refrigerants. Table 1 gives the average minimum concentrations of inhibitory explosion, which are calculated from the experimental results for R134a, R125 and R227ea and their impact on R290, R600, R600a, R32, R143a, and R152a. When the nonflammable refrigerants exceed the minimum inhibitory concentration in the air, flammable refrigerants at any concentrations will not explode [7].

The inhibition efficiency of nonflammable refrigerants on the explosion limits of flammable refrigerants is influenced by: their chemical properties; temperature; ignition energy; test container volume: container geometry; the degree to which the flame has spread; and other factors. If the need for inerting concentration of HC compounds is higher than that of HFC compounds, and the ratio of $\mathrm{F}$ atoms in combustible HFC compounds is greater than the hydrogen atoms, the requirement for the inerting concentration will be lower. Furthermore, the inerting concentration will increase with an increase in the flammable refrigerant's temperature. The degree to which temperature 


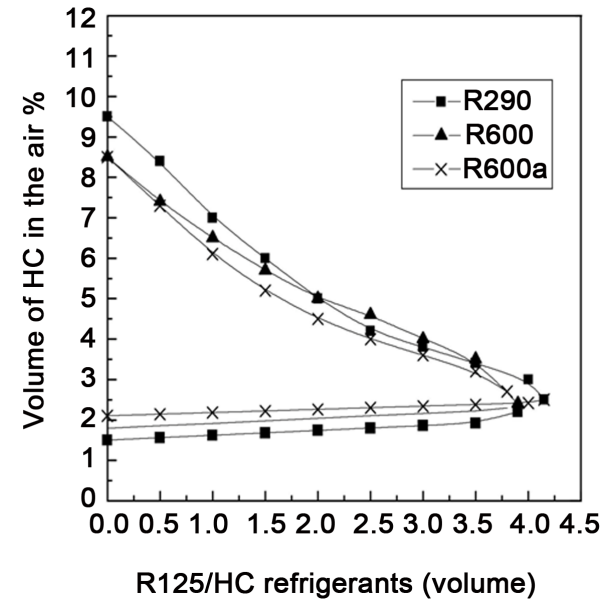

Figure 3. Effect of R125 on HC explosion limit.

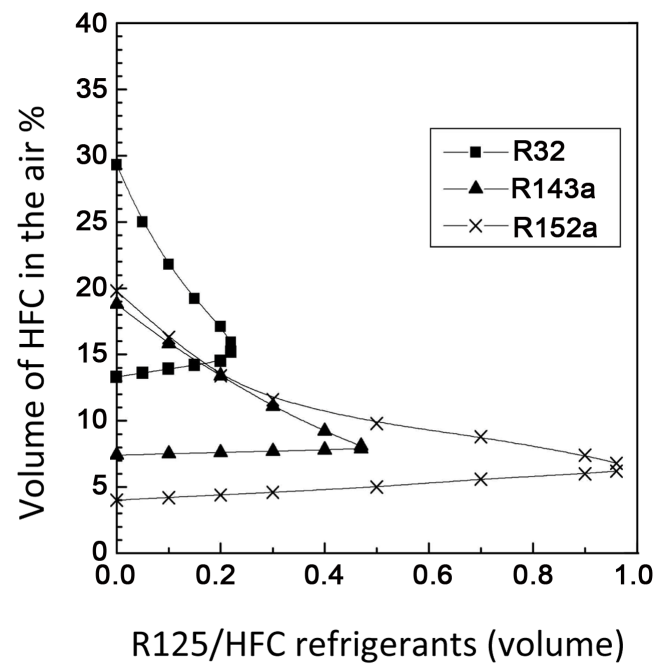

Figure 4. Effect of R125 on HFC explosion limit.

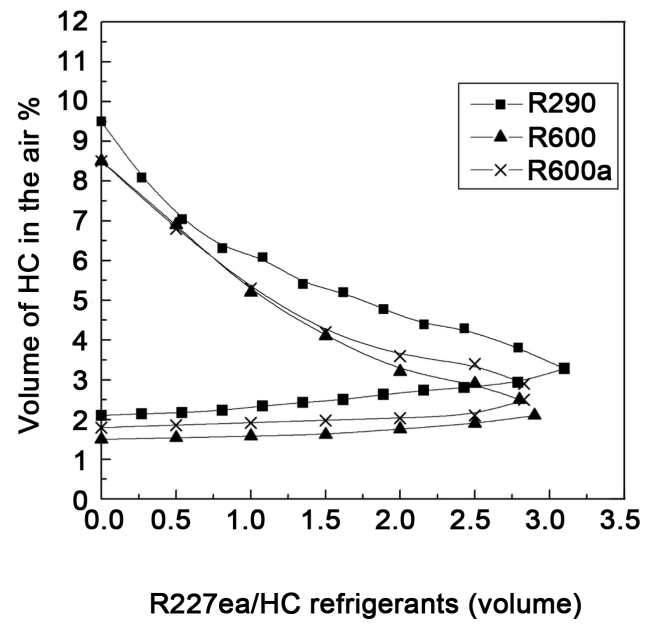

Figure 5. Effect of R227ea on HC explosion limit. 


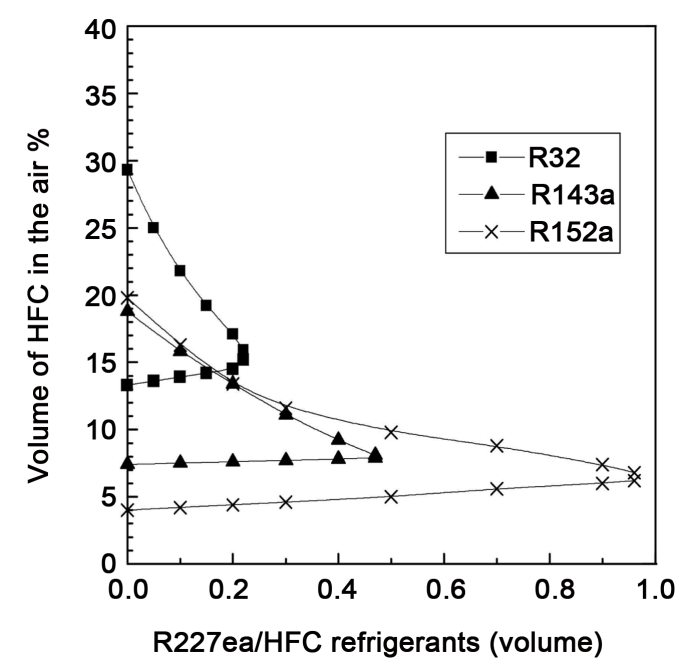

Figure 6. Effect of R227ea on HFC explosion limit.

Table 1. The minimum concentration of inert three nonflammable refrigerants on six flammable refrigerants (volume \%).

\begin{tabular}{ccccccc}
\hline Refrigerant code & $\mathrm{R} 290$ & $\mathrm{R} 600$ & $\mathrm{R} 600 \mathrm{a}$ & $\mathrm{R} 32$ & $\mathrm{R} 143 \mathrm{a}$ & $\mathrm{R} 152 \mathrm{a}$ \\
\hline Molecular formula & $\mathrm{C}_{3} \mathrm{H}_{8}$ & $\mathrm{C}_{4} \mathrm{H}_{10}$ & $\mathrm{C}_{4} \mathrm{H}_{10}$ & $\mathrm{CH}_{2} \mathrm{~F}_{2}$ & $\mathrm{CH}_{2} \mathrm{FCHF}_{2}$ & $\mathrm{CH}_{2} \mathrm{FCH}_{2} \mathrm{~F}$ \\
R134a & 13.87 & 10.12 & 10.8 & 8.11 & 8.82 & 15.13 \\
R125 & 10.53 & 9.50 & 9.60 & 4.32 & 5.21 & 7.15 \\
R227ea & 7.86 & 7.53 & 7.59 & 3.37 & 4.23 & 5.67 \\
\hline
\end{tabular}

Note: The experimental conditions are: room temperature $\left(17^{\circ} \mathrm{C}\right.$ to $\left.23^{\circ} \mathrm{C}\right)$, ambient atmospheric pressure, and 200 $\mathrm{W}$ ignition power.

will influence the inerting concentration is based on the variety of flammable refrigerants. Nonflammable refrigerants have a large inhibitory effect on the upper explosion limit, and a small inhibitory effect on the lower explosion limit.

For a fixed test system or device, the inerting concentration will increase with an increase in ignition energy; the degree to which it will increase depends on the type of flammable refrigerant, with the impact on HFC of flammable refrigerants being significantly greater than on HC. When measuring the inerting concentration using small containers, high ignition energy will cause the inerting concentration to significantly increase. In contrast, with low ignition energy (less than $100 \mathrm{~J}$ ), the volume of the test device has little influence on the inerting concentration. An increase in the degree of flame diffusion within the test device will result in a decrease in the inerting concentration, and this effect is huge when the ignition energy is less than $100 \mathrm{~J}$.

From the above analysis we can conclude that non-combustible HFC compounds in a small proportion cannot effectively inhibit the explosion limit of an HC refrigerant. Whereas using $\mathrm{CF}_{3} \mathrm{I}$ and other efficient fire-extinguishing agents in a relatively small proportion can successfully control the explosion limit of $\mathrm{HC}$ compounds. According to 1 to 3 experimental data, Figure 7 and Figure 8 show the effect of $\mathrm{CF}_{3} \mathrm{I}$ on the explo- 


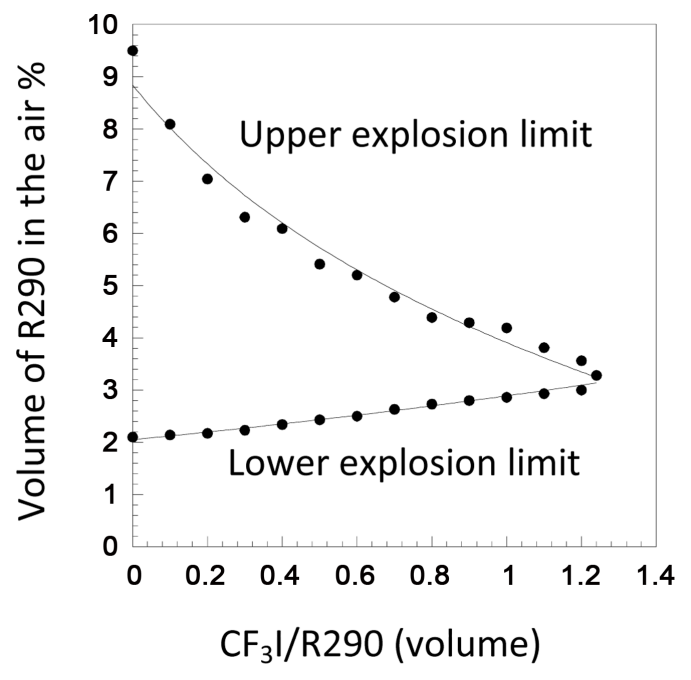

Figure 7. Effect of $\mathrm{CF}_{3} \mathrm{I}$ on R290 explosion limit.

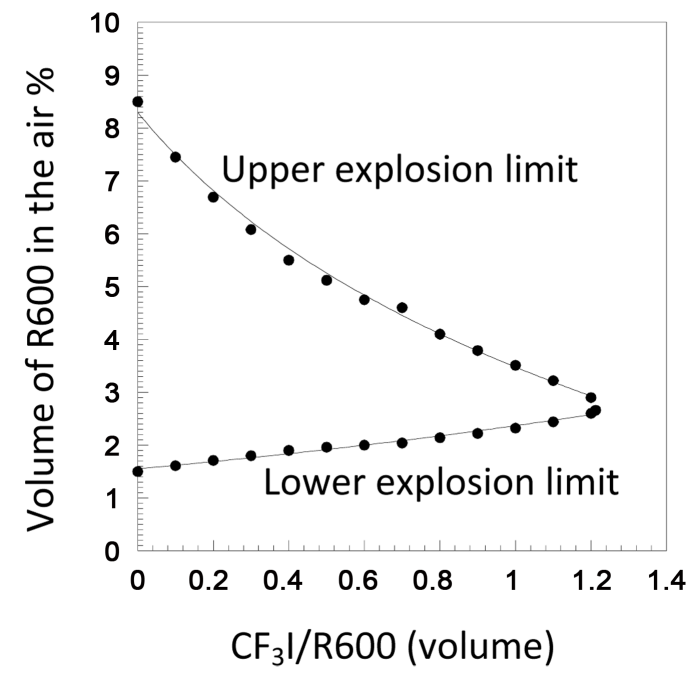

Figure 8. Effect of $\mathrm{CF}_{3} \mathrm{I}$ on R600 explosion limit.

sion limits of R290 and R600. The curves obtained are the same with the changing of Figures 1-6, which indicates the versatility of dealing with experimental data in this test.

\section{Calculating the Inhibition Concentration of Explosion Limits in Terms of a Mixture Containing No Combustible Refrigerants}

A key problem when faced with safely using combustible refrigerant mixtures is the question of how to determine the inhibiting explosion limit concentration of mixtures with combustible components. In this paper, a new method is put forward, which makes the number of components of the working group equal to the number of noncombustible workers. When combining one combustible component with one noncombustible component to form a new combustible mixture, we can use the correlation 
equations to compute the volume of each pair such that the ratio of each pair's concentrations reaches the critical concentration for combustion.

\subsection{Mixture with Two Flammable Refrigerants and One Nonflammable Refrigerant}

Let $A$ and $B$ be flammable refrigerants, and $C$ be a nonflammable refrigerant. The volume of the components is $V_{A}, V_{B}, V_{C}$. When the flammable refrigerant's $V_{A} / V_{B}$ has been determined, we can use the equations below to calculate the volume of the combustible component $V_{A}, V_{B}$ and nonflammable component's critical volume $V_{C R}$.

$$
\begin{gathered}
V_{A} / V_{B}=X \quad(X \text { is constant }) \\
V_{C A R} / V_{A}=R_{A C} \\
V_{C B R} / V_{B}=R_{B C} \\
V_{A}+V_{B}+V_{C R}=100 \\
V_{C R}=V_{C A R}+V_{C B R}
\end{gathered}
$$

Using Equations (7) through (11), the following equation group can be derived:

$$
\left\{\begin{array}{l}
V_{B}(I)=100 /\left(X(I)+X(I) \cdot R_{A C}+R_{B C}+1\right) \\
V_{A}(I)=X(I) \cdot V_{B} \\
V_{C}(I)=100-V_{A}(I)-V_{B}(I)
\end{array} I=1,2,3, \cdots, n\right.
$$

$V_{C A R}$ is the volume of component $C(\%)$, when the binary mixture of $C$ and $A$ reaches the ratio ( $R_{A C}$ defined below) of the critical flammable volume. Similarly, $V_{C B R}$ is the volume of component $\mathrm{C}$ (\%), when the binary mixture of $C$ and $B$ reaches the ratio of critical flammable volume. $R_{A C}$ is the critical flammable volume ratio of $A$ and $C$ mixed refrigerants; $R_{B C}$ is the critical flammable volume ratio of $B$ and $C$ mixed refrigerants. Formula (12) is an iteration form with different values of $X$, and Figure 9 and Figure 10 are examples of the calculation.

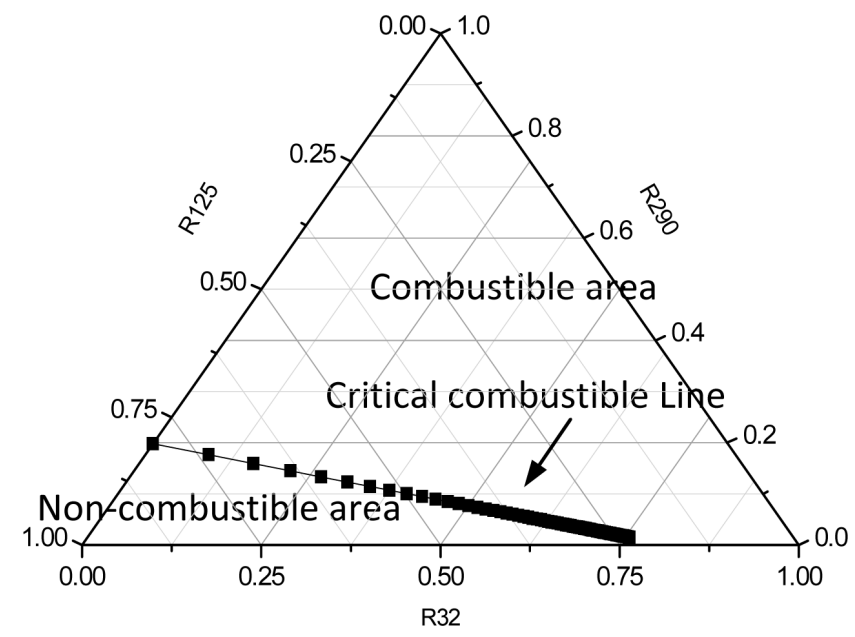

Figure 9. Flammable range of R32, R290 and R125. 


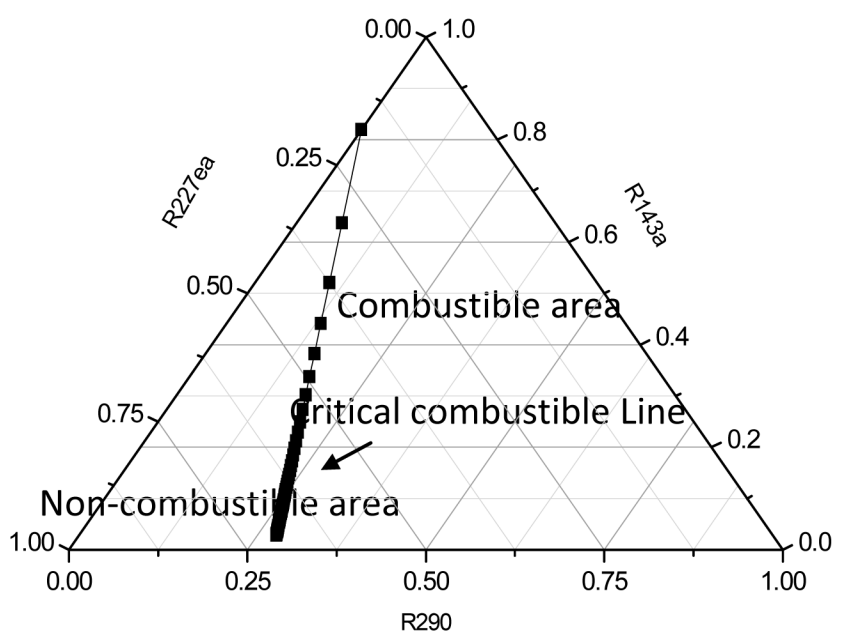

Figure 10. Flammable range of R290, R143a and R227ea.

\subsection{Mixture with One Flammable Component and Two Nonflammable Components}

Let $A, B$ and $C$ represent the flammable refrigerant and the two nonflammable refrigerants respectively, and $V_{A}, V_{B}$ and $V_{C}$ represent their separate volumes. When the nonflammable refrigerant $V_{B} / V_{C}$ is known, $V_{A}, V_{B}$ and the critical volumetric fraction $V_{A R}$ of $A$ can be calculated using the following equations:

$$
\begin{gathered}
V_{B} / V_{C}=Y \quad(Y \text { is constant }) \\
V_{B} / V_{A B R}=R_{A B} \\
V_{C} / V_{A B R}=R_{A C} \\
V_{A R}+V_{B}+V_{C}=100 \\
V_{A R}=V_{A B R}+V_{A C R}
\end{gathered}
$$

Using Equations (13) through (17), we derive the following equation group:

$$
\left\{\begin{array}{l}
V_{C}(I)=100 / Y(I)+Y(I) / R_{A B}+1 / R_{B C}+1 \\
V_{B}(I)=Y(I) \cdot V_{C}(I) \quad I=1,2,3, \cdots, n \\
V_{A}(I)=100-V_{B}(I)-V_{C}(I)
\end{array}\right.
$$

$V_{A B R}$ is the volume ratio of the explosion limit (\%) when the mixture with $A$ and $B$ reaches the critical suppression explosion concentration. $V_{A C R}$ is the critical volume ratio of the explosion limit (\%) of the mixture with $A$ and $C$. Equation (18) is the iterative form with a different value for $Y$. Figure 11 and Figure 12 are examples of the calculation.

\subsection{Analysis}

A model for estimating the two mixtures' critical suppression explosion concentrations is established. One of the mixtures consisted of two flammable components with one nonflammable component, and the other consisted of one flammable and two non- 


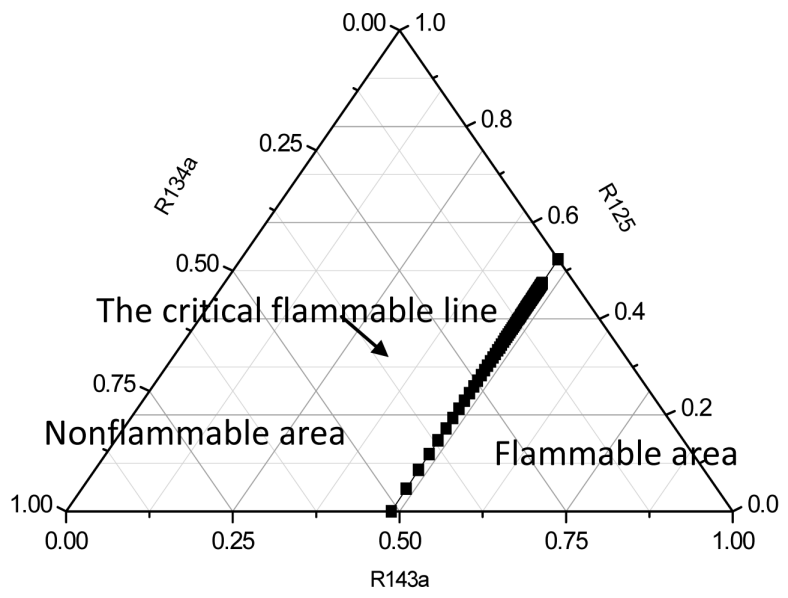

Figure 11. Flammable range of R143a, R125 and R134a.

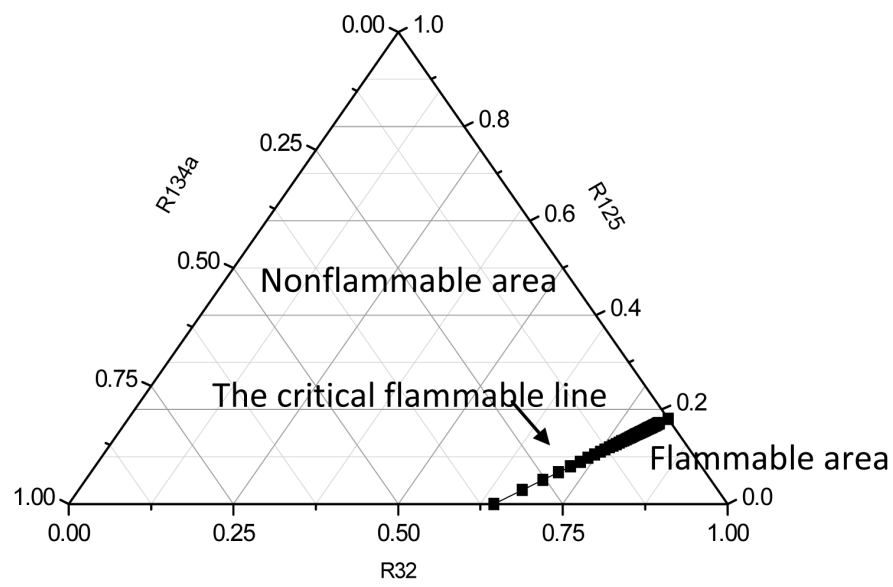

Figure 12. Flammable range of R32, R125 and R134a.

flammable components. The critical concentration ratio can be obtained from the explosion limit curve described in this study.

Since the model calculation is based on experimental data, the calculation results are consistent with experimental results. The relative error between the calculated results and the experimental results is generally less than $10 \%$. The model is used in conjunction with the explosion limit curves of 7 refrigerants and 14 groups of mixed refrigerants described in this paper, and can be used to evaluate critical suppression explosion concentrations of ternary mixtures with 7 refrigerants and any nonflammable refrigerants. Using this calculation method to guide the critical inhibition explosion concentration experiments for ternary mixtures with nonflammable refrigerants, can greatly reduce the number of experiments and hence the cost.

\section{Conclusions}

From the above analysis we can draw the following conclusions:

1) The explosion limit of flammable refrigerants in all published papers, is generally 
obtained using a small explosion vessel and a small ignition source [8], and is measured at normal atmospheric temperature levels. The actual range of explosion limits of flammable refrigerants is greater than the experimental data. Therefore, certain safety factors must be considered when selecting the experimental data.

2) As there are many methods to determine flammable gas explosion limits [9], the results obtained by different methods show certain differences. In order to unify the explosion limit of flammable refrigerants, the method for determining a combustible gas explosion limit in air should take the national standard GB/T12447-90 into account. The explosion limits for the 18 groups of mixed refrigerants measured by this paper can be used in engineering practice.

3) A model to estimate two mixtures' critical suppression explosion concentrations is established. The model of two mixtures is two flammable components with one nonflammable component and one flammable component with two nonflammable components. The critical inhibition explosion concentration ratio determined by using this model can be used for inhibition of flammable refrigerant mixtures.

4) Flammable refrigerants such as R290, R600 and R600a are ideal substitutes for CFCs and HCFCs, but they can only be used in refrigerators with small volume since their flammability limits their use [10]. Azeotropic or non-azeotropic refrigerants are obtained by combining Halon alternatives $\left(\mathrm{CF}_{3} \mathrm{I}, \mathrm{R} 134 \mathrm{a}\right)$ with flammable refrigerants (R290, R600 and R600a). These refrigerants with different concentration ratios can reduce the explosion limits range and the flammability of flammable refrigerants, raise the lower explosion limit and ignition energy. When Halon substitutes reach a certain concentration, they can render the refrigerant mixture to be an inert nonflammable refrigerant, which can solve the safety problem of flammable refrigerants. Therefore, this method can be used to make substitutes such as the ideal R12 and R22 refrigerants.

\section{References}

[1] Noto, T., Babushok, V., Hamins, A. and Tsang, W. (1998) Inhibition Effectiveness of Halogenated Compounds. Combustion and Flame, 112, 147-160.

[2] Hamins, A. and Bortthwick, P. (1998) Suppression of Ignition over a Heated Metal Surface. Combustion and Flame, 112, 161-170.

[3] Richard, R.G. and Shankland Ruffalo, I.R. (1995) Flammability of Alternate Refrigerants. Proceedings of the 18th International Refrigeration Conference, 8, 384-391.

[4] Babushok, V., Tsang, W., Linteris, G.T. and Reinelt, D. (1998) Chemical Limits to Flame Inhibition. Combustion and Flame, 115, 147-160.

[5] Smith, N.D. and Tufts, M.W. (1992) Flammable Properties of HFC Refrigerants-Some Fundamental Considerations, Presentation 2.2, ARI Flammable Workshop-Summary and Proceedings. Air-Conditioning and Refrigeration Institute (ARI), Arilington, VA.

[6] Hynes, R.G. and Mackie, J.C. (1998) Inhibition of Premixed Hydrogen-Air Flames by 2-H Heptafluoropropane. Combustion and Flame, 113, 554-565.

[7] Battin-Leclerc, F., Glaude, P.A., Come, G.M. and Baronnet, F. (1997) Inhibiting Effect of $\mathrm{CF}_{3} \mathrm{I}$ a Jet-Stirred Reactor. Combustion and Flame, 109, 285-292.

[8] Hu, D. (1989) Studies of the Detonability Limit and the Transition from Deflagration to 
Detonation for Detonability Gases. Explosion and Shock Waves, 9, 266-274.

[9] Zhao, H.Y. (1996) The Theory of Gas and Dust Explosion. Beijing Institute of Technology Press, Beijing.

[10] Naboerte, K., Xiong, G. and Li, H. (1983) Combustible Gas and Steam Safety Technical Parameters Manual. Mechanical Industry Press, Beijing, 96-327. 


\section{Experimental Apparatus}

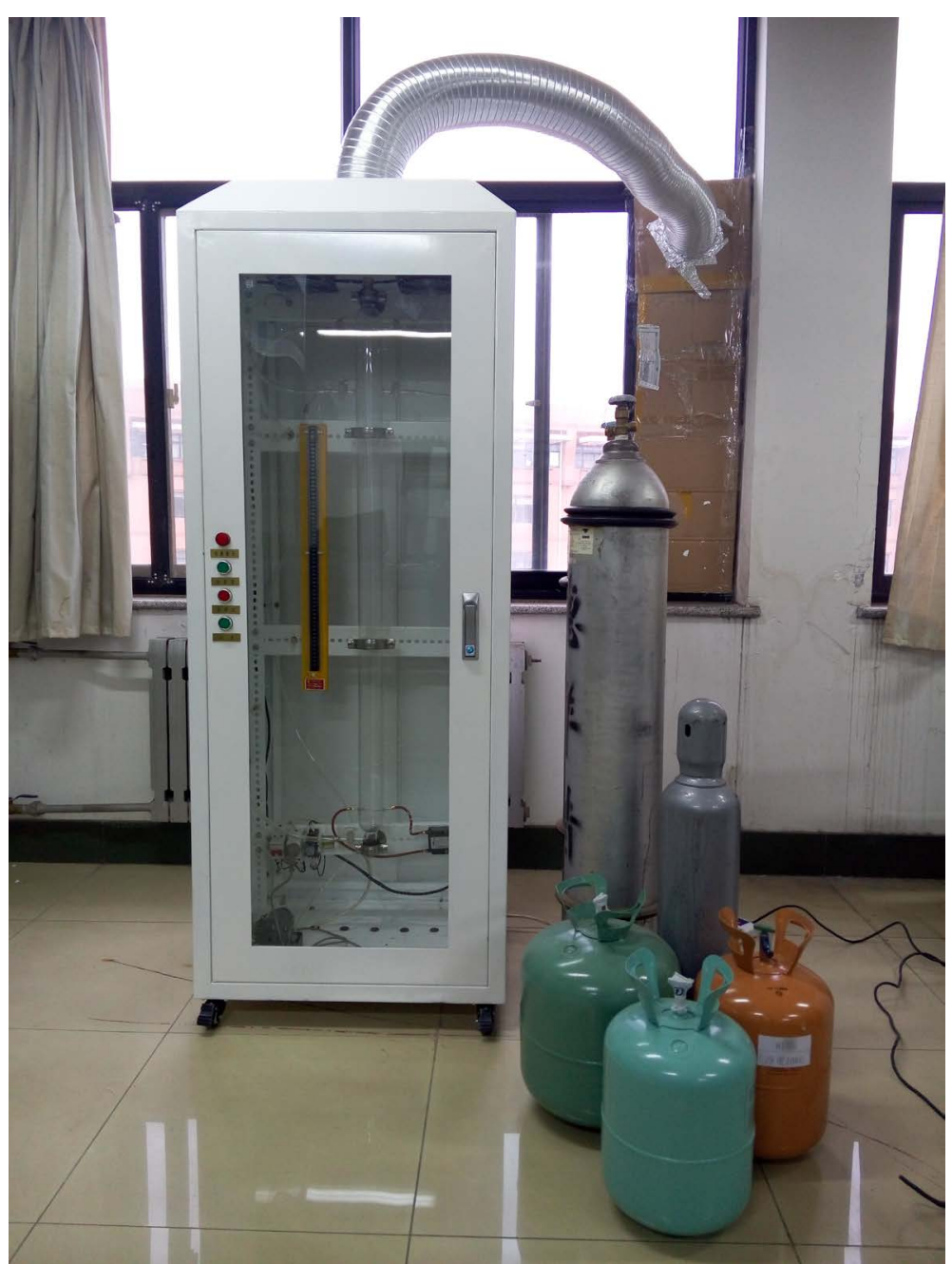

\section{Scientific Research Publishing}

Submit or recommend next manuscript to SCIRP and we will provide best service for you:

Accepting pre-submission inquiries through Email, Facebook, LinkedIn, Twitter, etc. A wide selection of journals (inclusive of 9 subjects, more than 200 journals)

Providing 24-hour high-quality service

User-friendly online submission system

Fair and swift peer-review system

Efficient typesetting and proofreading procedure

Display of the result of downloads and visits, as well as the number of cited articles

Maximum dissemination of your research work

Submit your manuscript at: http://papersubmission.scirp.org/

Or contact jsea@scirp.org 